\title{
Onychomycosis due to opportunistic molds ${ }^{*}$
}

\author{
Erick Obed Martínez-Herrera ${ }^{1}$ \\ Diana Luz Tejada-García ${ }^{3}$ \\ Roberto Arenas ${ }^{2}$
}

\author{
Stefanie Arroyo-Camarena ${ }^{2}$ \\ Carlos Francisco Porras-López ${ }^{1}$
}

DOI: http:/ / dx.doi.org/10.1590/abd1806-4841.20153521

\begin{abstract}
A bstract: BACKGROUND: Onychomycosis are caused by dermatophytes and Candida, but rarely by non- dermatophyte molds. These opportunistic agents are filamentous fungi found as soil and plant pathogens.

OвJеctives: To determine the frequency of opportunistic molds in onychomycosis.

METHODS: A retrospective analysis of 4,220 cases with onychomycosis, diagnosed in a 39-month period at the Institute of Dermatology and Skin surgery "Prof. Dr. Fernando A. Cordero C." in Guatemala City, and confirmed with a positive $\mathrm{KOH}$ test and culture.

RESUlTS: 32 cases $(0.76 \%)$ of onychomycosis caused by opportunistic molds were confirmed. The most affected age group ranged from 41 to 65 years (15 patients, $46.9 \%)$ and females were more commonly affected (21 cases, $65.6 \%$ ) than males. Lateral and distal subungual onychomycosis (OSD-L) was detected in 20 cases (62.5\%). The microscopic examination with $\mathrm{KOH}$ showed filaments in 19 cases $(59.4 \%)$, dermatophytoma in 9 cases (28.1\%), spores in 2 cases (6.25\%), and filaments and spores in 2 cases (6.25\%). Etiologic agents: Aspergillus sp., 11 cases (34.4\%); Scopulariopsis brevicaulis, 8 cases (25.0\%); Cladosporium sp., 3 cases (9.4\%); A cremonium sp., 2 cases (6.25\%); Paecilomyces sp., 2 cases (6.25\%); Tritirachium oryzae, 2 cases (6.25\%); Fusarium sp., Phialophora sp., Rhizopus sp. and Alternaria alternate, 1 case $(3.1 \%)$ each.

CONCLUSIONS: We found onychomycosis by opportunistic molds in $0.76 \%$ of the cases and DLSO was present in $62.5 \%$. The most frequent isolated etiological agents were: A spergillus sp. and Scopulariopsis brevicaulis.
\end{abstract}

Keywords: Fungi; Onychomycosis; Opportunistic infections

\section{INTRODUCTION}

The term onychomycosis is derived from the Greek words onychos (meaning nail) and mycosis (meaning fungal infection). ${ }^{1}$

The nomenclature of fungal infections proposed by the International Society for Human and Animal Mycology suggest that the term onychomycosis should be replaced: by tinea unguium, when the etiological agent is a dermatophyte; by onyxis, when yeasts are the cause; by ungual candidiasis, when the agent is Candida; and by ungual mycosis if the causal agent is an opportunistic mold. ${ }^{1}$

It is difficult to establish the pathogenicity of opportunistic, non-dermatophyte molds on nails, as in all opportunistic infections. There are always a number of criteria that need to be fulfilled. The culture must be free of dermatophytes and the opportunistic mold should be observed in the microscopic examination using 10 to $40 \%$ potassium hydroxide (KOH). ${ }^{2}$

Opportunistic non-dermatophyte molds (NDM) are found in nature as soil saprophytes and plant pathogens. They are fast growing, have universal distribution and are often unnoticed laboratory contaminants. ${ }^{3}$

The most commonly described species of NDM are: Scopulariopsis brevicaulis, Fusarium sp., Acremonium sp., A spergillus sp., Scytalidium sp. and Onychocola canadienses. ${ }^{3}$ A wide group of NDM species and some saprophyte yeast may also affect the nail plate directly. These include some species of the genera Alternaria, Curvularia, Trichospor on and Hendersonula. ${ }^{4}$

Received on 09.03.2014

Approved by the Advisory Board and accepted for publication on 10.06.2014

Study conducted at the Institute of Dermatology and skin surgery "Prof. Dr. Fernando A. Cordero C.", Guatemala City, Guatemala.

Financial Support: Institute of Dermatology and skin surgery "Prof. Dr. Fernando A. Cordero C.", Guatemala City, Guatemala.

Conflict of Interest: None.

Institute of Dermatology and Skin surgery "Prof. Dr. Fernando A. Cordero C." - Guatemala City, Guatemala.

'Dr. Manuel Gea González' General Hospital - Mexico City, Mexico.

Hospital "Omar Torrijos Herrera" - Panamá.

C2015 by Anais Brasileiros de Dermatologia 
Onychomycosis is the most difficult to treat superficial mycosis. It is a chronic infection that is prone to relapse. Therefore, it is important to identify the causative agent to ensure that the appropriate treatment is employed for each case. ${ }^{5}$

\section{MATERIALS AND METHODS}

In the interest of determining the frequency of onychomycosis by opportunistic NDM, a retrospective study was carried out from July 2008 to September 2011 at the Institute of Dermatology and Skin surgery "Prof. Dr. Fernando A. Cordero C." , in Guatemala City.

A total of 4,220 cases of onychomycosis were studied in that period, and 32 cases $(0.76 \%)$ were diagnosed as onychomycosis by NDM.

We reviewed the data collected in the Medical Mycology Unit of the Institution, and analyzed the following variables: sex, age, residence, history, associated diseases, clinical type, localization, mycological study with $\mathrm{KOH}$ and culture.

\section{RESULTS}

Of a total of 4,220 onychomycosis cases diagnosed in a 39-month period, 32 were confirmed as onychomycosis caused by opportunistic molds (0.76\%).

During data analysis, a predominance of females was observed (21 cases, $65.63 \%$ ). (Graph 1). The most affected age group was $41-65$ years (15 patients, $46.9 \%)$, followed by $18-40$ years (12 patients, $37.5 \%$ ), older than 65 years (4 patients, $12.5 \%$ ) and $0-17$ years $(3.1 \%)$.

With regard to the place of residence, 6 cases $(18.7 \%)$ lived in the rural area and 26 cases $(81.3 \%)$ lived in the urban area. History of clinical manifestations varied from 1 month to 30 years, with an average of 7 years (Table 1). Regarding to the clinical form, distal and lateral subungual onychomycosis (DLSO) predominated, accounting for 20 cases $(62.5 \%)$, followed by total dystrophic onychomycosis (TDO), which accounted for 12 cases (37.5\%) (Graph 2).

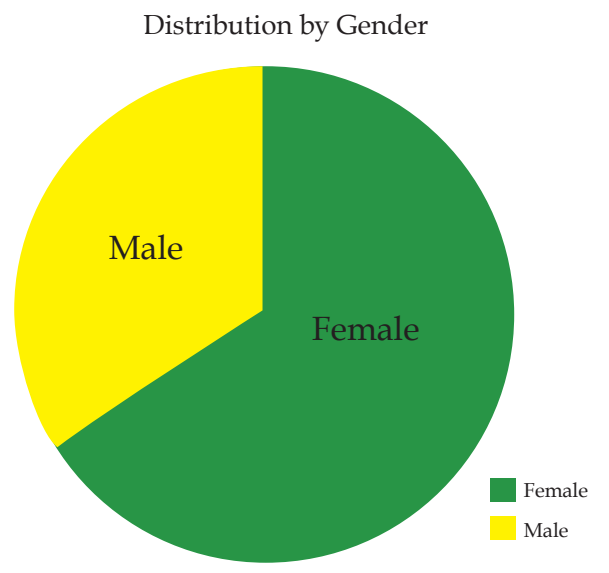

GRAPH 1: Distribution of patients by gender
We also found a predominance of toenail involvement, which accounted for 30 cases (93.75\%). There were only 2 cases of fingernail onychomycosis $(6.25 \%)$. The mycological study with $\mathrm{KOH}$ was positive for filaments in 19 cases $(59.4 \%)$, for dermatophytoma in 9 cases $(28.1 \%)$, for spores in 2 cases $(6.25 \%)$ and for filaments and spores in 2 cases $(6.25 \%)$.

The following etiologic agents were identified: A spergillus sp., $\mathrm{n}=11$ cases $(34.4 \%)$; Scopulariopsis brevicaulis, $\mathrm{n}=8$ cases $(25.0 \%)$; Cladosporium sp., $\mathrm{n}=3$ cases $(9.4 \%)$; A cremonium sp., $\mathrm{n}=2$ cases (6.25\%); Paecilomyces sp., $\mathrm{n}=2$ cases $(6.25 \%)$; Tritirachium oryzae, $\mathrm{n}=$ 2 cases $(6.25 \%)$; Fusarium sp., $\mathrm{n}=1$ cases $(3.1 \%)$; Phialophora $\mathrm{sp}, \mathrm{n}=1$ case $(3.1 \%)$; R hizopus $\mathrm{sp}, \mathrm{n}=1$ case $(3.1 \%)$; and Alternaria alternata, $\mathrm{n}=1$ case $(3.1 \%)$ (Table 2). It is noteworthy that 3 control cultures were performed in each case, confirming the results described above. Patients' occupation: $46.9 \%(n=15)$ were housewives and $12,5 \%(n=4)$ were students.

Table 1: Epidemiological study data

\begin{tabular}{lll}
\hline Variables & & \\
\hline $\begin{array}{c}\text { Gender } \\
\text { Female } \\
\text { Male }\end{array}$ & 21 & $65.63 \%$ \\
A ge & 11 & $34.37 \%$ \\
$0-17$ & 1 & $3.1 \%$ \\
$18-40$ & 12 & $37.5 \%$ \\
$41-65$ & 15 & $46.9 \%$ \\
$>65$ & 4 & $12.5 \%$ \\
D uration & & \\
$\quad$ Shorter & 1 Month & \\
Longer & 30 Years & \\
Average & 7.02 Years & \\
Clinical Form & & \\
Dlso & 20 & $62.5 \%$ \\
Tdo & 12 & $37.5 \%$ \\
\hline
\end{tabular}

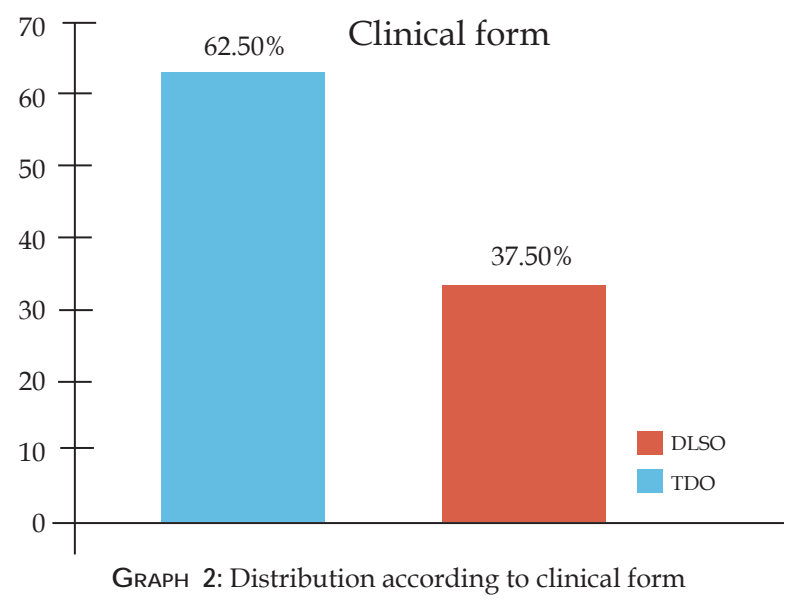


TABLE 2: Etiologic agents: obtained from nail samples

\begin{tabular}{lll}
\hline ETIO LOG IC A G EN T & $\begin{array}{l}\text { N umber } \\
\text { of cases }\end{array}$ & Frequency \% \\
\hline A spergillus sp & 11 & $34.4 \%$ \\
Scopulariopsis brevicaulis & 8 & $25.0 \%$ \\
Cladosporium sp & 3 & $9.40 \%$ \\
A cremonium sp & 2 & $6.25 \%$ \\
Paecilomyces sp & 2 & $6.25 \%$ \\
Tritirachium oryzae & 2 & $6.25 \%$ \\
Fusarium sp & 1 & $3.10 \%$ \\
Phialophora sp & 1 & $3.10 \%$ \\
Rhizopus sp & 1 & $3.10 \%$ \\
A Iternaria alternata & 1 & $3.10 \%$ \\
Total & 32 & $100 \%$ \\
\hline
\end{tabular}

\section{DISCUSSION}

According to Crespo et al., the isolation rates of opportunistic NDM in nails range from 2 to $25 \% .{ }^{2} \mathrm{How}$ ever, it should be noted that the prevalence of onychomycosis caused by molds in the general population is unknown, since all published studies are conducted in selected populations with patients with nail dystrophy or clinical suspicion of onychomycosis attending to dermatological consultation or clinical laboratories. ${ }^{6}$

The data collected over a period of 39 months at the Institute of Dermatology and Skin surgery "Prof. Dr. Fernando A. Cordero C.", in Guatemala City, showed an incidence of $0.76 \%$ of onychomycosis caused by opportunistic NDM, which is between the ranges reported in other studies.

It is necessary to use direct microscopic examination and culture in the study of onychomycosis for the identification of the etiologic agent. ${ }^{7}$ The direct microscopic examination is performed with 10 to $40 \%$ potassium hydroxide; this helps to dissolve keratin for visualization of fungal material. The morphology of hyphae will show the probably fungal etiology: regular hyphae indicate dermatophytes and irregular hyphae give suspicion of NDM. Abasti et al. state that at least two successive cultures must be performed to check the initial diagnosis. ${ }^{3}$ In our study, data were corroborated by 3 additional cultures.

Some factors predispose to the development of fungal infections and they may be helpful in understanding the results of the cultures, such as: patient origin, work environment, exposure to affected human or animals. ${ }^{4}$

Onychomycoses caused by Candida are closely related to work activities that require frequent water immersion of hands. Abasti et al. found a higher frequency of onychomycosis caused by opportunistic NDM in housewives. ${ }^{3}$

The five most common organisms worldwide are: Scopulariopsis brevicaulis, Fusarium sp., Aspergillus sp., Scytalidium dimidiatum and Acremonium sp.. In Colombia (South America), there are studies sug- gesting the Fusarium species as the most common..$^{8,9}$ In European countries, the most frequent species are: Scopulariopsis brevicaulis, A spergillus sp., A cremonium sp. and Fusarium sp. . ${ }^{10}$ The species found in this study were: A spergillus sp., Scopulariopsis brevicaulis, Cladosporium sp., A cremonium sp., and Paecilomyces sp..

It is noteworthy that onychomycoses are more common in the first toes of people over 60 years of age, with peripheral vascular disease, anatomical alterations, nail pathology and endocrine diseases. ${ }^{2}$ The toenails was the most affected anatomic area in this study, with a total of 30 cases $(93.75 \%)$. There were only 2 cases in the fingernails (6.25\%). Escobar et al..$^{8}$ observed a predominance of onychomycosis of toenails in female patients $(62 \%)$ aged 21 to 50 years $(91 \%) .{ }^{11}$ Similar results were found in the present study, with 21 cases $(65.63 \%)$ in females and 11 cases in males (46.9\%). The most affected age group was 41 to 65 years, with 15 patients (46.9\%).

Roberts et al. described four clinical forms for dermatophytes and other filamentous fungi: distal and lateral subungual onychomycosis (DLSO), white superficial onychomycosis (WSO), proximal subungual onychomycosis (PSO) and total dystrophic onychomycosis (TDO). ${ }^{12}$ The most common variant is the DLSO, and it is basically caused by dermatophytes, mainly $\mathrm{T}$. rubrum. The WSO is less common than the DLSO and is related to immunosuppression..$^{13}$ Elewski et al. estimate that about $10 \%$ of onychomycosis are presented under this clinical form; it is more frequent in toenails and especially in the first toe. ${ }^{14} \mathrm{~T}$. mentagrophytes varinterdigitale is the most common causative agent of WSO, but may be caused by other opportunistic molds such as: A spergillus terreus, A cremoniun potronii and Fusarium oxysporum. ${ }^{11,15}$ The PSO is a rare clinical form, mostly caused by $T$. rubrum, which equally affects fingernails and toenails. TDO is the final stage of onychomycosis; there is an involvement of the nail matrix and the entire nail is destroyed, appearing friable keratotic masses. ${ }^{13}$ The data collected in our study show a predominance of DLSO (62.5\%), followed by total dystrophic onychomycosis (TDO) (37.5\%).

The diagnostic criteria necessary to detect onychomycosis caused by opportunistic molds should be fulfilled, in order to ensure adequate treatment. This is because the therapeutic management of onychomycosis by filamentous fungi non-dermatophytic is complex and unsatisfactory and much more difficult than that of tinea unguium. ${ }^{6,16}$

\section{CONCLUSION}

Most of our findings are similar to other studies and it is worth noting that it is important to make a complete mycological study (microscopic examination with $\mathrm{KOH}$ and culture) in patients with suspicion of onychomycosis.] 


\section{REFERENCE}

1. López-Jodra 0 , Torres-Rodriguez J. Especies fúngicas poco comunes responsables de onicomicosis. Rev Iberoam Micol. 1999;16:S11-5.

2. Crespo V, Delgado V. Micosis ungueales. In: Erchiga VC,Florencio VD.Atlas de Micología Cutánea. Madrid, España: Loky \& Dimas; 2006. p. 9-11.

3. Asbati M, Smythe B, Cavallera E. Onicomicosis por hongos no dematofitos. Estudio retrospectivo en 4 años. Rev Soc Ven Microbiol. 2002;22:147-52.

4. Araujo AJG, Bastos OMP, Souza MAJ, Oliveira JC. Onychomycosis caused by emergent fungi: clinical analysis, diagnosis and revisión. An Bras Dermatol. 2003;78:445-55

5. Salas I, Chavez 0. Agentes de Onicomicosis en Costa Rica. Rev Costarric Cienc Méd. 2004;25:43-7.

6. Del Palacio A, Pazos C, Cuétara S. Onicomicosis por hongos filamentosos no dermatofitos. Enferm Infecc Microbiol Clin. 2001;19:439-42.

7. Kaur R, Kashyap B, Bhalla P. Onychomycosis-Epidemiology, Diagnosis and Management. Indian J Med Microbiol. 2008;26:108-16.

8. Escobar ML, Carmona-Fonseca J. Onicomicosis por hongos ambientales no dermatofíticos. Rev Iberoam Micol. 2003;20:6-10.

9. Morales CA, Solórzano A, Rojas AP. Características epidemiológicas y clínicas de las onicomicosis causadas por Fusarium spp. en un centro de referencia de Bógota, Colombia, 2001-2010. Rev Asoc Colomb Dermatol. 2013;21:21-8.

10. Tosti A, Piraccini BM, Lorenzi S. Onychomycosis caused by nondermatophytic molds: clinical features and response to treatment of 59 cases. J Am Acad Dermatol. 2000;42:217-24.

11. Elewski BE. Onychomycosis: pathogenesis, diagnosis and management. Clin Microbiol Rev. 1998;11:415-29.

12. Roberts DT, Taylor WD, Boyle J; British Association of Dermatologists. Guidelines for treatment of onychomycosis. Br J Dermatol. 2003:148:402-10.

13. Ballesté R, Mousqués N, Gezuele E. Onicomicosis. Rev Med Uruguay. 2003;19:93106.

14. Elewski BE, Charif MA. Prevalence of onychomycosis in patients attempting a dermatology clinic in northeastern Ohio for other conditions. Arch Dermatol. 1997;133:1172-3.

15. Zaias N, Glick B, Rebell G. Diagnosing and treating onychomycosis. J Fam Pract. 1996;42:513-8.

16. Moreno G, Arenas R. Other fungi causing onychomycosis. Clin Dermatol. 2010;28:160-3.

\author{
M AILING ADDRESS: \\ Erick $\mathrm{O}$ bed $\mathrm{M}$ artínez-H errera \\ Calz San Juan 32-11 Z-7 - Guatemala \\ E-mail: martinezerickh@gmail.com
}

How to cite this article: Marinez-Herrera EO, Arroyo-Camarena S,Tejeda-García DL, Porras-Lopez CF, Arenas R. Onychomycosis due to opportunistic molds. An Bras Dermatol. 2015;90(3):334-7. 